Acta Crystallographica Section F

Structural Biology

and Crystallization

Communications

ISSN 1744-3091

\section{Structure of the SARS coronavirus main proteinase as an active $\mathrm{C}_{2}$ crystallographic dimer}

Ting Xu, ${ }^{a}$ Amy Ooi, ${ }^{a}$ Hooi Chen Lee, ${ }^{a}$ Rupert Wilmouth, ${ }^{a}$ Ding Xiang Liu ${ }^{b}$ and Julien Lescar $^{\mathrm{a} *}$

${ }^{\mathbf{a}}$ School of Biological Sciences, Nanyang Technological University, 60 Nanyang Drive, Singapore 637551, Singapore, and ${ }^{\mathbf{b}}$ Institute of Molecular and Cell Biology, Singapore

Correspondence e-mail: julien@ntu.edu.sg

Received 26 August 2005 Accepted 17 October 2005 Online 20 October 2005

PDB Reference: SARS coronavirus main proteinase, 2c3s, 2c3ssf.

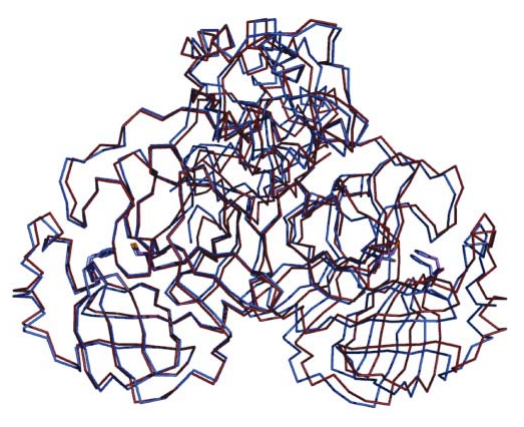

(C) 2005 International Union of Crystallography All rights reserved
The $34 \mathrm{kDa}$ main proteinase $\left(\mathrm{M}^{\mathrm{pro}}\right)$ from the severe acute respiratory syndrome coronavirus (SARS-CoV) plays an important role in the virus life cycle through the specific processing of viral polyproteins. As such, SARS-CoV $\mathrm{M}^{\text {pro }}$ is a key target for the identification of specific inhibitors directed against the SARS virus. With a view to facilitating the development of such compounds, crystals were obtained of the enzyme at $\mathrm{pH} 6.5$ in the orthorhombic space group $P 2{ }_{1} 2_{1} 2$ that diffract to a resolution of $1.9 \AA$. These crystals contain one monomer per asymmetric unit and the biologically active dimer is generated via the crystallographic twofold axis. The conformation of the catalytic site indicates that the enzyme is active in the crystalline form and thus suitable for structurebased inhibition studies.

\section{Introduction}

Severe acute respiratory syndrome (SARS) is a severe form of pneumonia. Its transmission pattern, high mortality rate and possible re-emergence in the future make SARS a serious threat for which neither efficient therapy nor vaccine is currently available. The disease is caused by a member of the coronavirus family: the SARS coronavirus (SARS-CoV; Fouchier et al., 2003). Following viral entry into cells, two polyproteins named pp1a and pp1ab, with molecular weights of 486 and $790 \mathrm{kDa}$, respectively, are synthesized (Rota et al., 2003). During the viral life cycle, pp1a and pp1ab are processed into 15 putative non-structural proteins by two viral proteases: the papainlike protease and the main proteinase $\mathrm{M}^{\text {pro }}$ (also named the 3C-like protease; $3 \mathrm{CL}^{\text {pro; }}$ reviewed in Ziebuhr et al., 2000). In SARS-CoV, $\mathrm{M}^{\text {pro }}$ is responsible for the cleavage of 11 sites in the replicase polyproteins (Snijder et al., 2003), releasing viral enzymes needed for replication, such as the RNA-dependent RNA polymerase and the helicase, as well as other accessory proteins and non-structural proteins the functions of which are not fully understood. Thus, given its pivotal role in the viral life cycle, $\mathrm{M}^{\text {pro }}$ is an attractive target for the development of drugs directed against the SARS virus. Threedimensional structures of $\mathrm{M}^{\text {pro }}$ enzymes have been reported for several coronaviruses including human CoV (HCoV229E; Anand et al., 2003), porcine transmissible gastroenteritis virus (TGEV; Anand et al., 2002) and SARS-CoV (Yang et al., 2003). In this study, using an Escherichia coli overexpression system, we purified the SARS-CoV $\mathrm{M}^{\text {pro }}$ and obtained a novel crystal form at $\mathrm{pH} 6.5$ that diffracts to high resolution and contains one monomer per asymmetric unit. The active-site residues and the oxyanion hole adopt a functional conformation, indicating that this crystal form might be useful for structure-based drug design.

\section{Experimental}

\subsection{Protein expression and purification}

The DNA fragment encoding the SARS-CoV M ${ }^{\text {pro }}$ strain SIN 2774 (Ruan et al., 2003) was amplified by PCR using Pfu polymerase (Stratagene) and cloned into pMAL-c2x (New England Biolabs) incorporating the maltose-binding protein (MBP) at the N-terminus of SARS-CoV M ${ }^{\text {pro }}$. The forward primer (5'-TACTAATTGAAGGA GTTCGGGTTTTAGGAAAATGG-3') contains an XmnI site 
(bold). The reverse primer (5'-AGCCGGATCCTTATTGGAAGGT AACACCAG-3') contains a BamHI site (bold) downstream of the stop codon TAA. Four additional amino acids (IEGR) were introduced to facilitate the removal of MBP by factor Xa. Transformed BL21(DE3) E. coli cells were grown at $310 \mathrm{~K}$ in LB media supplemented with $0.2 \%$ glucose until an $\mathrm{OD}_{600 \mathrm{~nm}}$ of $0.6-0.8$ was attained. IPTG was added to a final concentration of $1 \mathrm{~m} M$ and the temperature was lowered to $303 \mathrm{~K}$. After $2 \mathrm{~h}$, cells were harvested by centrifugation at $8000 \mathrm{~g}$ for $10 \mathrm{~min}$, resuspended in buffer $A(20 \mathrm{mM}$ Tris- $\mathrm{HCl} \mathrm{pH} \mathrm{7.4,} 50 \mathrm{~m} M \mathrm{NaCl}, 1 \mathrm{~m} M$ EDTA) and lysed by sonication for $20 \mathrm{~min}$, followed by centrifugation at $20000 \mathrm{~g}$ for $20 \mathrm{~min}$ at $277 \mathrm{~K}$. The supernatant was loaded onto an Econo-column (Bio-Rad)

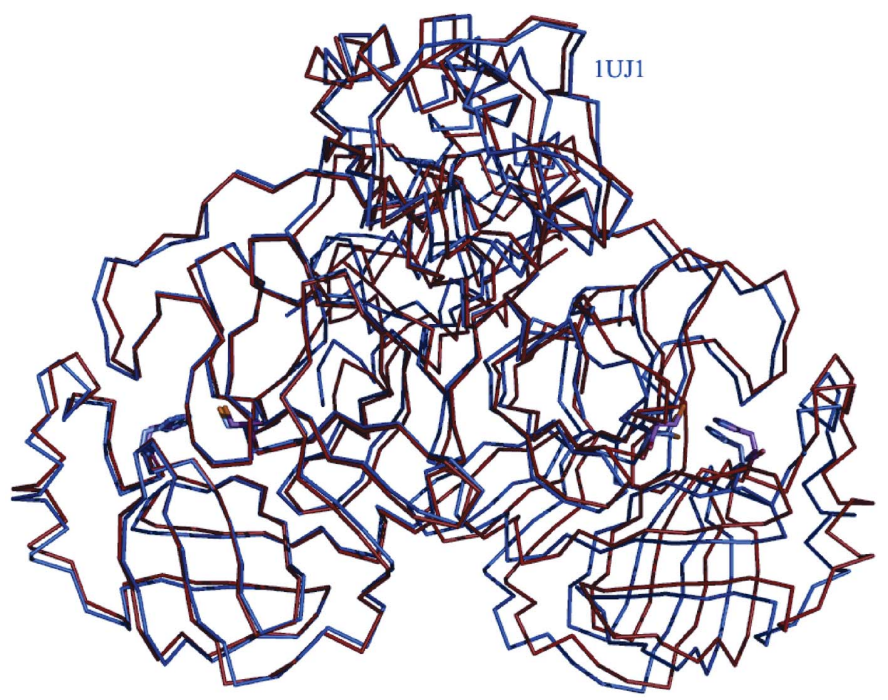

(a)

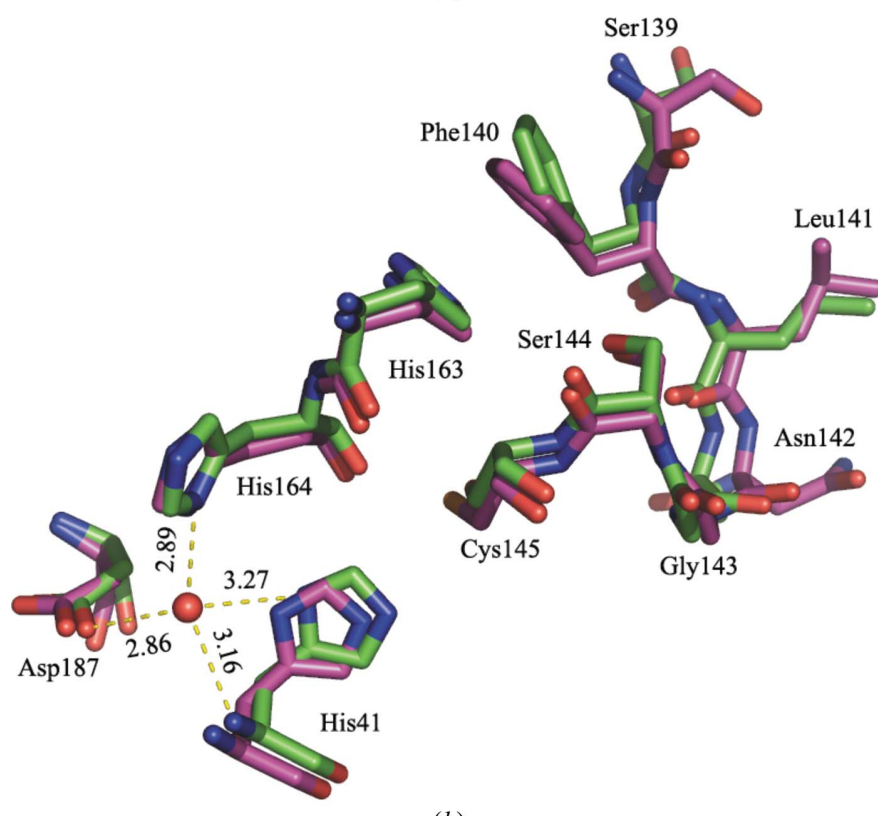

Figure 1

(b)

(a) Overall superposition of the $\mathrm{C}^{\alpha}$ traces from the SARS-CoV $\mathrm{M}^{\text {pro }}$ monomer present in our asymmetric unit (coloured red, PDB code $2 \mathrm{c} 3 \mathrm{~s}$ ) with the active monomer $A$ of Yang et al. (2003) (shown in blue, PDB code 1uj1, chain $A$ ). A residual rotation of $4.5^{\circ}$ is needed to then bring the two equivalent monomers $B$ into coincidence. The active-site residues of each monomer are represented as sticks. ( $b$ ) Detailed view of the active site represented as green sticks $(2 \mathrm{c} 3 \mathrm{~s}$, this work) superimposed onto the active monomer $A$ of SARS-CoV M $^{\text {pro }}$ (1uj1, chain $A$ ). The putative hydrogen bonds (dashed lines) formed by the spatially conserved water molecule (red sphere) are shown.
Table 1

Data-collection and refinement statistics.

Values in parentheses refer to the highest resolution shell.

\begin{tabular}{ll}
\hline Data-collection statistics & \\
Space group & $P 2_{1} 2_{1} 2$ \\
Unit-cell parameters $(\AA)$ & $a=107.7, b=44.9, c=54.2$ \\
Resolution range $(\AA)$ & $28-1.90(1.95-1.90)$ \\
Unique reflections & 19895 \\
Redundancy & $8.0(5.9)$ \\
Completeness $(\%)$ & $97.9(88.2)$ \\
$I / \sigma(I)$ & $4.6(2.2)$ \\
$R_{\text {merge }} \dagger(\%)$ & $7.8(31.4)$ \\
$V_{\mathrm{M}}\left(\AA^{3} \mathrm{Da}^{-1}\right)$ & 1.95 \\
Refinement statistics & \\
$R$ 未 $(\%)$ & $22.5(27.5)$ \\
$R_{\text {free value }(\%)}$ & $26.4(31.2)$ \\
No. of protein atoms & $2302[301$ residues] \\
No. of solvent molecules & 211 \\
No. of reflections in working set & 19880 \\
No. of reflections in test set & 1077 \\
Mean temperature factor $\left(\AA^{2}\right)$ & 35.21 \\
R.m.s.d. bond lengths $(\AA)$ & 0.006 \\
R.m.s.d. bond angles $\left({ }^{\circ}\right)$ & 1.31 \\
R.m.s.d. dihedral angles $\left({ }^{\circ}\right)$ & 24.7 \\
Ramachandran plot & \\
Most favoured region $(\%)$ & 87.7 \\
Additionally allowed regions $(\%)$ & 11.1 \\
Generously allowed regions $(\%)$ & 0.8 \\
Disallowed regions $(\%)$ & 0.4 \\
&
\end{tabular}

$\dagger R_{\text {merge }}=\sum_{h k l}|I-\langle I\rangle| / \sum_{h k l} I . \quad \ddagger R=\sum\left|F_{\text {calc }}-F_{\text {obs }}\right| / \sum\left|F_{\text {obs }}\right|$.

packed with amylose resin (New England Biolab) equilibrated with buffer $A$ and incubated overnight at $277 \mathrm{~K}$. The fusion protein was eluted at $277 \mathrm{~K}$ using $20 \mathrm{~m} M$ Tris- $\mathrm{HCl} \mathrm{pH} \mathrm{7.4,} 50 \mathrm{~m} M \mathrm{NaCl}, 1 \mathrm{~m} M$ EDTA, $10 \mathrm{~m} M$ maltose and loaded onto a HiPrep 16/10 Q Sepharose FF column (Amersham) equilibrated with buffer $B(20 \mathrm{~m} M$ Tris- $\mathrm{HCl}$ $\mathrm{pH}$ 8.0, $50 \mathrm{~m} M \mathrm{NaCl}, 1 \mathrm{~m} M$ EDTA). Proteins were eluted using a linear $\mathrm{NaCl}$ concentration gradient in buffer $C(20 \mathrm{~m} M$ Tris- $\mathrm{HCl} \mathrm{pH}$ 8.0, $1 M \mathrm{NaCl}, 1 \mathrm{~m} M$ EDTA). Fractions containing MBP-SARS-CoV $\mathrm{M}^{\text {pro }}$ were pooled, concentrated by ultrafiltration at $3000 \mathrm{~g}$ (Centricon, Vivascience) and desalted in $20 \mathrm{~m} M$ Tris- $\mathrm{HCl} \mathrm{pH} 7.0,50 \mathrm{mM}$ $\mathrm{NaCl}, 1 \mathrm{~m} M \mathrm{CaCl}_{2}$ using PD-10 columns (Amersham). One unit of factor Xa was added per $142 \mu \mathrm{g}$ of fusion protein for $6 \mathrm{~h}$ at $297 \mathrm{~K}$. After cleavage, factor Xa was removed using a resin (Qiagen). Cleaved products were loaded onto an XK 16/20 phenyl Sepharose resin column (Amersham) equilibrated in buffer $D$ (12.5 $\mathrm{m} M$ Tris$\mathrm{HCl} \mathrm{pH} 7.0,300 \mathrm{~m} M \mathrm{NaCl}, 1 \mathrm{~m} M$ DTT, $0.1 \mathrm{~m} M$ EDTA). The recombinant SARS-CoV $\mathrm{M}^{\text {pro }}$ was eluted using buffer $E(12.5 \mathrm{mM}$ Tris-HCl pH 7.0, $1 \mathrm{~m} M$ DTT, $0.1 \mathrm{~m} M$ EDTA). Fractions containing SARS-CoV $\mathrm{M}^{\text {pro }}$ were pooled and the buffer changed to $10 \mathrm{~m} M$ Tris$\mathrm{HCl} \mathrm{pH} \mathrm{7.4,} 1 \mathrm{~m} M$ EDTA, $1 \mathrm{~m} M$ DTT for concentration to $5 \mathrm{mg} \mathrm{ml}^{-1}$ as determined using the Bradford method (Bio-Rad) with BSA as a standard and stored at $193 \mathrm{~K}$.

\subsection{Crystallization and data collection}

Crystals of SARS-CoV $\mathrm{M}^{\text {pro }}$ were grown using the hanging-drop vapour-diffusion method. Equal volumes $(1 \mu \mathrm{l})$ of protein and mother liquor were mixed over wells containing 0.1 $M$ MES pH 6.5 and $0.6 \mathrm{M}\left(\mathrm{NH}_{4}\right)_{2} \mathrm{SO}_{4}$ at $291 \mathrm{~K}$. Macroseeding produced thin elongated plate-like crystals over a period of one week. For data collection, crystals were soaked in a cryoprotecting solution containing $30 \%$ glycerol, $0.1 M$ MES, $0.6 M\left(\mathrm{NH}_{4}\right)_{2} \mathrm{SO}_{4} \mathrm{pH} 6.5$, before being mounted and cooled to $100 \mathrm{~K}$ in a nitrogen-gas stream (Oxford Cryosystems). Diffraction intensities were recorded at beamline ID14-4 at the European Synchrotron Radiation Facility, Grenoble, France on an ADSC CCD detector using an attenuated beam of $0.125 \times 0.050 \mathrm{~mm}$. Integration, scaling and merging of the intensities 
were carried out using programs from the $C C P 4$ suite (Collaborative Computational Project, Number 4, 1994). Data-collection and refinement statistics are presented in Table 1.

\subsection{Structure determination and refinement}

The structure of SARS-CoV $\mathrm{M}^{\text {pro }}$ was readily solved by molecular replacement using the program $A M o R e$ from the $C C P 4$ suite with the SARS-CoV $\mathrm{M}^{\text {pro }}$ structure deposited as PDB code 1uj1 as a search model. The program REFMAC5 was used for refinement cycles, which were alternated with rebuilding sessions using the program $O$ (Jones et al., 1991). 5\% of the reflections were set aside to monitor the progress of refinement using the $R_{\text {free }}$ factor. Water molecules, added automatically using ARP/wARP (Perrakis et al., 1999), were checked by visual inspection. The quality of the model was assessed using PROCHECK (Laskowski et al., 1993). Structure superposition was performed with $L S Q K A B$ (Collaborative Computational Project, Number 4, 1994).

\section{Results and discussion}

\subsection{Overall structure of SARS-CoV $M^{\text {pro }}$}

The model comprises one monomer per asymmetric unit (residues 1-301). Five residues from the C-terminus are not visible in the electron-density map and have been omitted. Residues 1-101 (domain I) and 102-184 (domain II) form the chymotrypsin-like double- $\beta$-barrel structure which is observed in several viral proteases including picornaviruses, togaviruses and flaviviruses (Babe \& Craik, 1997). The C-terminal $\alpha$-helical domain (residues 201-301) of SARS$\mathrm{CoV} \mathrm{M}^{\text {pro }}$ is required for activity, since a truncated fragment comprising only its catalytic domain displays a significant decrease in enzymatic activity (Bacha et al., 2004). Structural and functional studies of coronavirus $\mathrm{M}^{\text {pro }}$ have shown that dimerization is required for maximal protease activity. In this respect, a prominent role is played by the seven amino-terminal amino acids, which adopt an extended conformation making extensive contacts with domain II of the other monomer and ensuring the formation of a catalytically competent active site (Yang et al., 2003). In our crystal form, the active dimer is generated through the crystallographic twofold. No contact is established by Ser1, which is mobile as shown by a higher than average temperature factor. The path of the main chain, however, closely follows that observed in previously reported active monomers, with an r.m.s deviation of $0.80 \AA$ for 300 equivalent mainchain atoms (PDB code 1uj1 chain $A$; Yang et al., 2003) (Fig. 1a). This latter crystal form belongs to space group $P 2_{1}$ and contains one dimer in the asymmetric unit with quasi-twofold symmetry. This indicates that the N-terminal residue is not absolutely required for the active site to adopt an active conformation.

A figure showing the distribution of the thermal factors of the SARS-CoV main proteinase is available as supplementary material. ${ }^{\mathbf{1}}$

\footnotetext{
${ }^{\mathbf{1}}$ Supplementary material is available from Crystallography Journals Online (Reference: SW5004).
}

\subsection{Structure of the active site}

The substrate-binding site is located in a cleft between the two $\beta$-barrels. The catalytic Cys145-His41 dyad (with the cysteine thiol acting as the nucleophile) is used instead of the classical Ser-His-Asp triad of serine proteases (Fig. 1b). Although the crystals were obtained at $\mathrm{pH} 6.5$, a value which is presumably near the $\mathrm{p} K_{\mathrm{a}}$ value of His residues in the substrate-binding site and where the enzyme shows a slightly reduced activity, the conformation of the active site indicates an active enzyme (Fig. $1 b$ ). The immediate vicinity of the active site is involved in extensive intermolecular contacts with neighbouring molecules. Thus, this crystal form is likely to be more suitable for studies involving soaking or co-crystallization of small compounds rather than long peptides. Interestingly, during the course of preparation and submission of this manuscript, related crystal forms of SARS-CoV $\mathrm{M}^{\text {pro }}$ have been reported by Hsu et al. (2005) and by Tan et al. (2005).

We are grateful to Dr Ed Liu from the Genome Institute of Singapore for providing us with the clones from the SARS virus. Financial support from the Singapore Biomedical (03/1/21/20/291) and National Medical Research Councils (NMRC/SRG/001/2003 to $\mathrm{JL}$ laboratory) is acknowledged as well as access to data-collection facilities at ESRF.

\section{References}

Anand, K., Palm, G. J., Mesters, J. R., Siddell, S. G., Ziebuhr, J. \& Hilgenfeld, R. (2002). EMBO J. 21, 3213-3224.

Anand, K., Ziebuhr, J., Wadhwani, P., Mesters, J. R. \& Hilgenfeld, R. (2003). Science, 300, 1763-1767.

Babe, L. M. \& Craik, C. S. (1997). Cell, 91, 427-430.

Bacha, U., Barrila, J., Velazquez-Campoy, A., Leavitt, S. A. \& Freire, E. (2004). Biochemistry, 43, 4906-4912.

Collaborative Computational Project, Number 4 (1994). Acta Cryst. D50, 760763.

Fouchier, R. A., Kuiken, T., Schutten, M., van Amerongen, G., van Doornum, G. J., van den Hoogen, B. G., Peiris, M., Lim, W., Stohr, K. \& Osterhaus, A. D. (2003). Nature (London), 423, 240.

Hsu, M. F., Kuo, C. J., Chang, K. T., Chang, H. C., Chou, C. C., Ko, T.-P., Shr, H. L., Chang, G. G., Wang, A. H.-J. \& Liang, P. H. (2005). J. Biol. Chem. 280, 31257-31266.

Jones, T. A., Zou, J. Y., Cowan, S. W. \& Kjeldgaard, M. (1991). Acta Cryst. A47, 110-119.

Laskowski, R. A., Moss, D. S. \& Thornton, J. M. (1993). J. Mol. Biol. 231, 10491067.

Perrakis, A., Morris, R. \& Lamzin, V. S. (1999). Nature Struct. Biol. 6, 458-463.

Rota, P. A. et al. (2003). Science, 300, 1394-1399.

Ruan, Y. J. et al. (2003). Lancet, 361, 1779-1785.

Snijder, E. J., Bredenbeek, P. J., Dobbe, J. C., Thiel, V., Ziebuhr, J., Poon, L. L., Guan, Y., Rozanov, M., Spaan, W. J. \& Gorbalenya, A. E. (2003). J. Mol. Biol. 331, 991-1004.

Tan, J., Verschueren, K. H. G., Anand, K., Shen, J., Yang, M., Xu, Y., Rao, Z., Bigalke, J., Heisen, B., Mesters, J., Chen, K., Shen, X., Jiang, H. \& Hilgenfeld, R. (2005). In the press.

Yang, H., Yang, M., Ding, Y., Liu, Y., Lou, Z., Zhou, Z., Sun, L., Mo, L., Ye, S., Pang, H., Gao, G. F., Anand, K., Bartlam, M., Hilgenfeld, R. \& Rao, Z. (2003). Proc. Natl Acad. Sci. USA, 100, 13190-13195.

Ziebuhr, J., Snijder, E. J. \& Gorbalenya, A. E. (2000). J. Gen. Virol. 81, 853879. 